\title{
Article \\ Smartphone-Based NFC Potentiostat for Wireless Electrochemical Sensing
}

\author{
Karnpimon Krorakai ${ }^{1}$, Supannika Klangphukhiew ${ }^{1}$, Sirinan Kulchat ${ }^{2}$ and Rina Patramanon ${ }^{1,3, *(D)}$ \\ 1 Department of Biochemistry, Faculty of Science, Khon Kaen University, Khon Kaen 40000, Thailand; \\ karnpimon.k@kkumail.com (K.K.); supannika.k@kkumail.com (S.K.) \\ 2 Department of Chemistry, Faculty of Science, Khon Kaen University, Khon Kaen 40000, Thailand; \\ sirikul@kku.ac.th \\ 3 Protein and Proteomics Research Center for Commercial and Industrial Purpose (ProCCI), \\ Khon Kaen University, Khon Kaen 40000, Thailand \\ * Correspondence: narin@kku.ac.th; Tel.: +66-84-599-9123
}

Citation: Krorakai, K.

Klangphukhiew, S.; Kulchat, S.;

Patramanon, R. Smartphone-Based NFC Potentiostat for Wireless Electrochemical Sensing. Appl. Sci. 2021, 11, 392. https://doi.org/ 10.3390/app11010392

Received: 19 December 2020 Accepted: 30 December 2020 Published: 3 January 2021

Publisher's Note: MDPI stays neutral with regard to jurisdictional clai$\mathrm{ms}$ in published maps and institutional affiliations.

Copyright: (C) 2021 by the authors. Licensee MDPI, Basel, Switzerland. This article is an open access article distributed under the terms and conditions of the Creative Commons Attribution (CC BY) license (https:// creativecommons.org/licenses/by/ $4.0 /)$

\begin{abstract}
Most electrochemical sensing requires affordable, portable and easy-to-use electrochemical devices for use in point-of-care testing and resource-limited settings. This work presents the design and evaluates the analytical performance of a near-field communication (NFC) potentiostat, a flat card-sized electrochemical device containing a microchip for electrical analysis and an NFC antenna for smartphone connection. The NFC interface is a wireless connection between the microchip and smartphone to simplify measuring units and make the potentiostat into a passive operated device, running without a battery. The proposed potentiostat can perform the common electrochemical techniques including cyclic voltammetry and chronoamperometry with a current range and voltage range of $\pm 20 \mu \mathrm{A}$ and $\pm 0.8 \mathrm{~V}$. The performance of the NFC potentiostat is compared to a commercial benchtop potentiostat using ferricyanide as a standard solution. The results show that the NFC potentiostat is comparable to a commercial benchtop potentiostat for both cyclic voltammetry and chronoamperometry measurements. The application of the proposed potentiostat is demonstrated by measuring ascorbic acid concentration. As described, the NFC potentiostat, which is compatible with a smartphone, is low-cost, small in size and user-friendly. Thus, the device can be developed for on-site measurement to apply in various fields.
\end{abstract}

Keywords: potentiostat; battery-less; near-field communication; smartphone

\section{Introduction}

Electrochemical sensing has been developed and is widely applied in various fields including food safety and control [1-3], environmental monitoring [4-6] and clinical diagnostics [7-9], since it offers many advantages such as high sensitivity and selectivity, rapid detection and small sample volume [10-12]. Typically, a potentiostat is an electronic instrument used to perform electroanalytical measurements by controlling the voltage difference and measuring the current flow through an electrochemical cell $[13,14]$. However, the commercially available potentiostats that are suitable for the laboratory are large and expensive, with a price of several thousand dollars [15-17], which largely limits their application for point-of-care testing and in resource-limited settings. For these reasons, an electrochemical workstation needs to be portable, low-cost and easy to use to meet the demand for on-site measurement.

In recent years, there has been growing research in the development of low-cost and portable potentiostats. Some studies have developed inexpensive and open-source potentiostats that complement commercial laboratory potentiostats [18-21], but the instrument requires a computer to operate the detection process, analyze the data and display the results. These devices limit the application for home-based testing and in resource-limited settings. Moreover, those devices cannot easily transmit the data to the cloud for storage 
and cannot directly share data with related users such as physicians or healthcare services for clinical applications. With the rapid growth of smartphone users worldwide, which exceeds 3.5 billion in 2020 , accounting for $45.4 \%$ of the world's population and being projected to grow further in the next few years [22], the development of smartphone coupling with potentiostats is an increasing trend for electrochemical sensing systems. In these systems, smartphones can be connected with potentiostats through Bluetooth, Wi-Fi, USB or an audio port interface for supplying power, data transmission, data processing, result display and sharing [23]. There have been previous studies on the development of potentiostats interfaced with a smartphone for specific applications and techniques. Ainla et al. proposed an open-source "universal wireless electrochemical detector" (UWED) that interfaces with a smartphone using Bluetooth [24]. In addition, Cai et al. presented xenSTAT, which can connect to the phone via Bluetooth and can perform most electrochemical techniques [25]. In another study, ABE-Stat, developed by Jenkins et al., can perform electrochemical analyses including cyclic voltammetry (CV), differential pulse voltammetry (DPV), high impedance potentiometric measurements, and can connect wirelessly to a smartphone through Wi-Fi [26]. However, these devices often require wired connection with USB and audio port or need rigid batteries for wireless power through Bluetooth and Wi-Fi, which greatly limits simplification and miniaturization of the device, and also increases the cost and maintenance demands $[27,28]$.

Near-field communication (NFC) is short-range wireless connectivity that allows the smartphone or other device to communicate with devices containing an NFC tag. NFC is being implemented on most new generation smartphones, and is being rolled out for several applications, including identification and cashless payments [29,30]. This technology is nowadays a high potential technology for use as a wireless sensor platform [31]. NFC sensors provide inexpensive, portable and real-time monitoring, which has been utilized in the field of food [32,33], the environment [34,35] and healthcare [36-38]. The advantage over other wireless standards such as Wi-Fi, Bluetooth and ZigBee is that NFC can receive and transfer power between devices with a long battery lifetime or battery-free implementation of a sensor [31,39]. Some studies have demonstrated the integration of NFC technology with an electrochemical sensing platform. Kassal et al. presented a radio-frequency identification (RFID)/NFC wireless sensor tag capable of performing potentiometric measurement for use with $\mathrm{pH}$ and ion-selective electrodes [40]. For amperometric measurement, Steinberg et al. demonstrated a wireless potentiostat that communicated with a smartphone by NFC. This potentiostat is semi-autonomous and able to store chronoamperometric data and perform data analysis externally on the smartphone [41]. In addition, NFC-based chemical sensors have been used to determine uric acid and glucose concentration. Kassal et al. developed smart bandage biosensor interfaces with a wearable potentiostat that wirelessly transfers data for uric acid levels, a wound biomarker, to a computer, tablet or smartphone by RFID or NFC. The smart bandage provides highly sensitive and specific uric acid detection, which is useful for home-based patients and healthcare service providers [42]. Fedtschenko et al. demonstrated a wireless sensor system used to determine glucose concentration in tear fluid by chronoamperometry. This system transfers the measurement data wirelessly to a handheld reader using RFID and NFC [43]. For the application in cyclic voltammetry, Siegl et al. reported a sensor strip with an integrated circuit (IC) powered via NFC for cyclic voltammetry. The strip consists of an antenna, a chip, an electrode connector and an oscilloscope that monitors the output electrode voltages [44]. Therefore, we introduce an NFC potentiostat, a battery-free and flat card-sized device, which interfaces with a smartphone through near-field communication. In this study, we demonstrate the design and performance of an NFC potentiostat compared with a commercial benchtop potentiostat in chronoamperometry and cyclic voltammetry techniques. In this work, the NFC potentiostat was used to evaluate the concentration of ascorbic acid in deionized water and commercial drinking water. 


\section{Materials and Methods}

\subsection{Chemicals and Materials}

All chemicals used in this work were analytical grade and deionized water was used throughout the experiments. Potassium ferricyanide $\left(\mathrm{K}_{3}\left[\mathrm{Fe}(\mathrm{CN})_{6}\right]\right)$, potassium chloride $(\mathrm{KCl})$ and ascorbic acid were purchased from Sigma Aldrich (St. Louis, MO, USA). All electrochemical measurements including cyclic voltammetry and chronoamperometry were performed on an NFC potentiostat developed by Silicon Craft Technology PLC (Bangkok, Thailand) and a Galaxy Nexus smartphone (Samsung, Seoul, South Korea) with Android operating system. A CH instrument (CHI 611E, Texas Instruments Inc., Austin, TX, USA) was used as a standard instrument. A commercial screen-printed carbon electrode (TE100, Zensor R\&D Co., Ltd., Taichung City, Taiwan), consisting of a $3 \mathrm{~mm}$ diameter carbon working electrode, carbon counter electrode and $\mathrm{Ag} / \mathrm{AgCl}$ reference electrode, was used to perform the experiment.

\subsection{NFC Potentiostat Design}

The NFC potentiostat is designed in the form of a compact credit card having dimensions of $5.5 \mathrm{~cm} \times 8.6 \mathrm{~cm}$, consisting of a planar antenna, NFC microchip (SIC4341) and connector for electrode interface. The dimension of the NFC potentiostat is designed to ensure stable operation during tapping the mobile, while leaving some space for electrode insertion and solution drop. The NFC microchip harvests energy from the magnetic field emitted from a smartphone or RFID reader through a loop antenna realized from $1 \mathrm{oz}$. $(35 \mu \mathrm{m})$ copper trace on FR4-PCB. The printed circuit board was processed by PCBway (Shenzhen, China). The antenna consists of a 4-turn loop with a size of 4.5-by-3.0 cm maximum perimeter and $250 \mu \mathrm{m}$ conductor width and spacing. The antenna has anductance of 2.04 $\mu \mathrm{H}$ with a quality factor of 130, measured by LA-19-13-02 VNA from LA technique Ltd. (Surrey, UK) and couples to a microchip having a $50 \mathrm{pF}$ internal capacitance. This creates a parallel resonance circuit at a peak resonance frequency of $15.7 \mathrm{MHz}$, based on the $f r=1 / 2 \pi \sqrt{\mathrm{LC}}$ relationship. The resonance frequency of the antenna is set a bit higher than the operating frequency of $13.56 \mathrm{MHz}$ in order to compensate coupling effects from near-field operation. The maximum operating read distance from the antenna is $2 \mathrm{~cm}$, over which the potentiostat can still operate stably. The energy is regulated to the internal $1.8 \mathrm{~V}$ power supply for the internal potentiostat to cover a maximum operation range of $\pm 20 \mu \mathrm{A}$, an analog-to-digital data converter, a digital signal processor to convert raw data into measurement current information and an NFC analog front-end communication circuit to communicate with the smartphone or RFID reader.

\subsection{Android Application}

A user-friendly SIC4341-POTEN Android mobile application was developed to operate the NFC potentiostat. The main screen shows the detection method as depicted in Figure 1a. After selecting the electrochemical method, the user can set the parameters of the experiment as shown in Figure 1b. Next, the software allows the user to drop the substrate. Then, the screen automatically displays the voltammogram as presented in Figure 1c. After finishing the process, users press the "next" icon. Data were obtained as illustrated in Figure $1 \mathrm{~d}$. Three options are then available, namely: back to the main screen, perform the electroanalytical experiment again and export the data. The resulting data are stored as ".txt" files and transferred to a computer for the interpretation steps by ES File Explorer. The resulting data enable upload through the cloud (e-mail, social media or Dropbox) for sharing storage or remote analysis of the data. Furthermore, the application can be adapted to suit different analyte detection by reporting the concentration of the sample calculated from the embedded standard calibration in the system. 


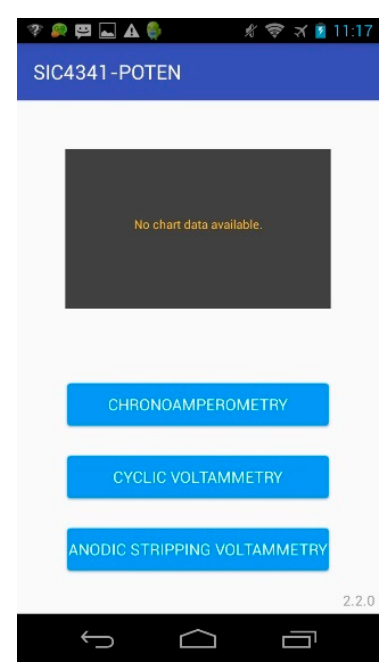

(a)

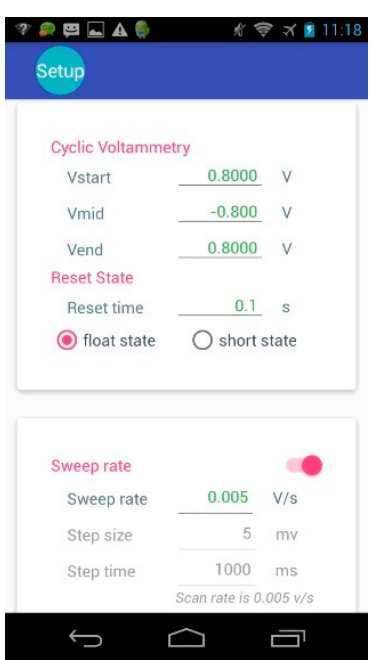

(b)

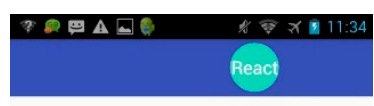

Conversion completed

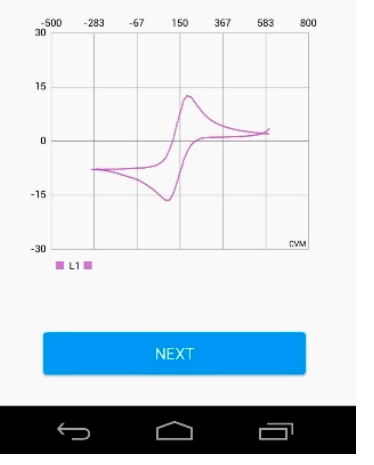

(c)

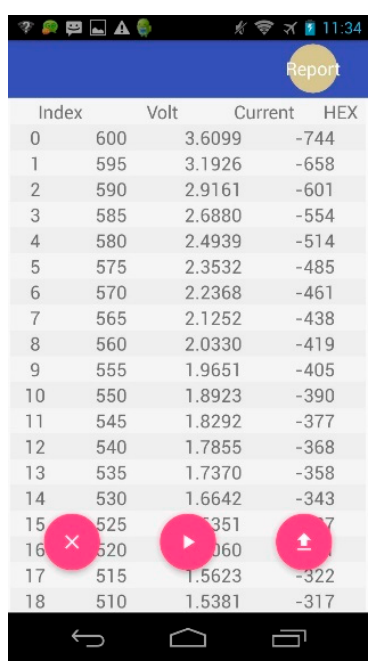

(d)

Figure 1. Smartphone screenshots showing the SIC4341-POTEN Android application: (a) initial screen, (b) electrochemical parameters settings, (c) cyclic voltammogram and (d) resulting data.

\subsection{Performance Test of the NFC Potentiostat}

To evaluate the performance of the NFC potentiostat, a commercial screen-printed carbon electrode consisting of a $3 \mathrm{~mm}$ diameter carbon working electrode, carbon counter electrode and an $\mathrm{Ag} / \mathrm{AgCl}$ reference electrode was used to perform cyclic voltammetry and chronoamperometry. The experiments on the NFC potentiostat were compared to a commercial laboratory potentiostat (CHI 611E, Texas Instruments Inc., Austin, TX, USA) used as a standard instrument. For each experiment, $100 \mu \mathrm{L}$ of potassium ferricyanide in $0.1 \mathrm{M} \mathrm{KCl}$ as a supporting electrolyte was applied on a screen-printed carbon electrode. The solution of potassium ferricyanide is a common analyte to test the performance of a potentiostat, because it exhibits a reversible electrochemical behavior and rapid oneelectron process $[45,46]$. Cyclic voltammetry was carried out over the potential range from -300 to $600 \mathrm{mV}$ at a scan rate of $5-200 \mathrm{mV} / \mathrm{s}$. For chronoamperometric detection, the fixed potential of $-100 \mathrm{mV}$ was applied to the working electrode and the current period of $0-30 \mathrm{~s}$ was recorded.

\subsection{Ascorbic Acid Measurement}

To demonstrate the application of the NFC potentiostat, the detection limit of standard ascorbic acid was determined by cyclic voltammetry. In this experiment, different concentrations of ascorbic acid, ranging from $0.1-1 \mathrm{mg} / \mathrm{mL}$, were drop-cast onto a commercial screen-printed carbon electrode. Cyclic voltammetry was performed over the potential range from 200 to $800 \mathrm{mV}$, and the current at $550 \mathrm{mV}$ was used to determine the ascorbic acid concentration. Commercial drinking water was spiked with ascorbic acid into different concentrations. The concentration of ascorbic acid in spiked commercial drinking water was analyzed from the calibration curve.

\section{Results}

\subsection{NFC Potentiostat Operation}

The main components of an NFC potentiostat are shown in Figure 2a, containing a loop antenna, NFC microchip (SIC4341) and connector for electrode interface designed on a printed circuit board with a credit card size. The details of the integrated circuit shown in Figure $2 \mathrm{~b}$ include (1) an analog part to connect between radio signals and controller, (2) digital controller and memory unit to control the operation of integrated circuits to respond to data transmission that operates at $13.56 \mathrm{MHz}$ in the high frequency (HF) radio band and 
is compatible with ISO14443A, and (3) the chemical sensor processing to measure signal responses from sensors.

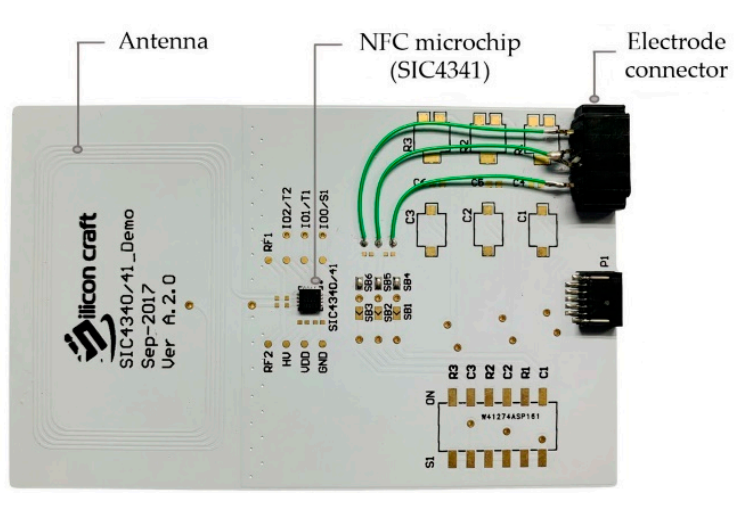

(a)

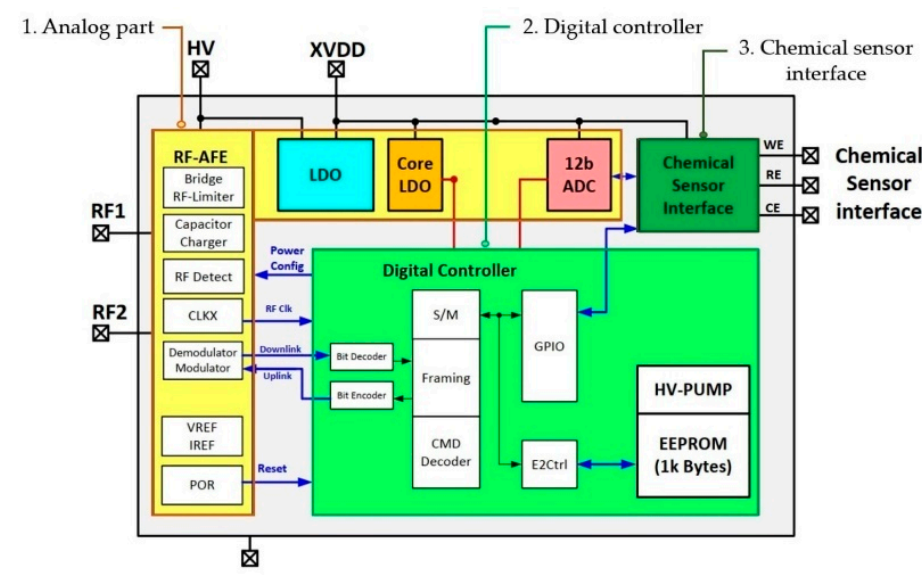

(b)

Figure 2. (a) Hardware components consisting of a planar antenna, near-field communication (NFC) microchip (SIC4341) and connector for electrode interface. (b) The integrated circuit of the NFC potentiostat, which includes (1) an analog part, (2) digital controller and memory unit and (3) the chemical sensor processing.

The operational steps of the NFC potentiostat are shown in the Supplementary Information Video S1. When an NFC smartphone approaches the NFC antenna, the NFC microchip is woken up by the radio frequency (RF) power from the induced magnetic field. If the incoming power is sufficiently high, indicated by its internal status, the NFC microchip starts initializing the system, activates the microchip peripheral devices and waits for a command from the NFC smartphone for further operations. The NFC microchip (SIC4341) consists of an internal potentiostat that is capable of supporting current measurement from chemical sensors at a maximum input current of $\pm 20 \mu \mathrm{A}$. The biasing voltage between working electrode and reference electrode can be between $-800 \mathrm{mV}$ and $800 \mathrm{mV}$, generated from the differential voltage of dual digital-to-analog converters (DACs) having full scale voltage of $1.28 \mathrm{~V}$ with a step of $5 \mathrm{mV}$. The NFC smartphone application controls the biasing voltage across the sensor by transmitting a command to adjust the DAC voltage. The amount of current from the sensor in the physical world is processed by the 10-bit analog-to-digital converter with a digital signal processor, and finally converted into digital data stored in internal memory, ready to be transmitted back to the NFC smartphone. The application on the NFC smartphone can periodically transmit commands to set the DACs, following biasing profiles such as cyclic voltammetry. The NFC smartphone can read the conversion result after each period to reconstruct a voltammetry waveform in the application graphic interface. As the timing can be set by the application, for example, for cyclic voltammetry, the sweep rate can be set on the application from $5 \mathrm{mV} / \mathrm{s}$ up to $1000 \mathrm{mV} / \mathrm{s}$. The application provides a graphic user interface (GUI) to set the three electrode terminals freely and flexibly to support various electrode arrangements.

\subsection{NFC Potentiostat Performance}

\subsubsection{Cyclic Voltammetry}

NFC potentiostat performance was compared to a commercial potentiostat $(\mathrm{CHI} 611 \mathrm{E}$, Texas Instruments Inc., Austin, TX, USA), which is a benchtop potentiostat designed to enable various electrochemical techniques to be performed in the laboratory. The cyclic voltammograms of $0.1,0.5$ and $1 \mathrm{mM}$ potassium ferricyanide in $0.1 \mathrm{M} \mathrm{KCl}$ at a scan rate of $100 \mathrm{mV} / \mathrm{s}$ performed on the NFC potentiostat and the commercial potentiostat are shown in Figure 3. The cyclic voltammograms showed a characteristic duck shape for a fully reversible one-electron reaction of ferricyanide. The results showed good agreement of cyclic 
voltammograms between the two devices. The higher the concentration of ferricyanide, the greater the current signals observed. The average and relative standard deviation (RSD) values of cathodic peak current and anodic peak current obtained from both potentiostats are listed in Table 1. As shown in the table, the relative standard deviation was less than $\pm 5 \%(n=3)$, indicating that both potentiostats had a good reproducibility for conducting the experiments.

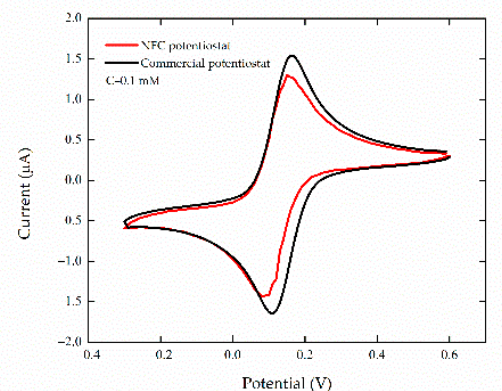

(a)

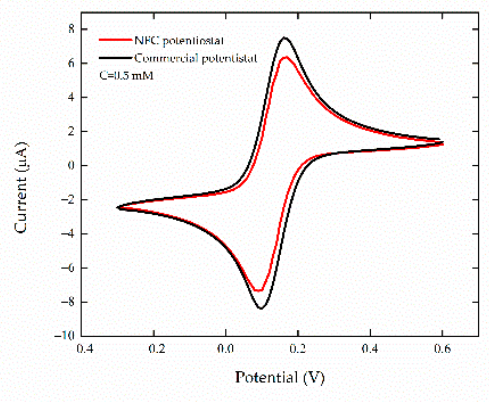

(b)

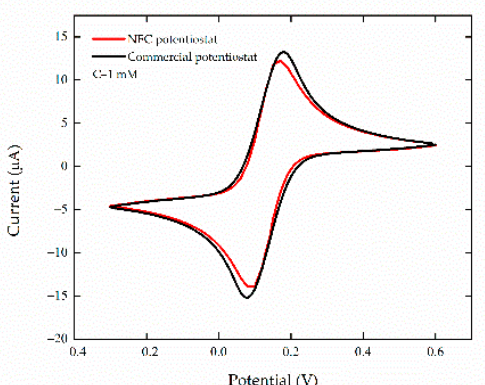

(c)

Figure 3. Cyclic voltammograms of (a) $0.1 \mathrm{mM}$, (b) $0.5 \mathrm{mM}$ and (c) $1 \mathrm{mM}$ potassium ferricyanide containing $0.1 \mathrm{M} \mathrm{KCl}$ using the NFC potentiostat (red) and a commercial potentiostat, $\mathrm{CHI} 611 \mathrm{E}$, (black) sweeping the potential between $-300 \mathrm{mV}$ and $600 \mathrm{mV}$, at a scan rate of $100 \mathrm{mV} / \mathrm{s}$.

Table 1. The average (AVG), standard deviation (SD) and relative standard deviation (RSD) of cathodic and anodic peak currents using the commercial potentiostat and the NFC potentiostat.

\begin{tabular}{|c|c|c|c|c|c|c|c|c|c|c|c|c|}
\hline & \multicolumn{6}{|c|}{ Commercial Potentiostat } & \multicolumn{6}{|c|}{ NFC Potentiostat } \\
\hline & \multicolumn{2}{|c|}{$0.1 \mathrm{mM}$} & \multicolumn{2}{|c|}{$0.5 \mathrm{mM}$} & \multicolumn{2}{|c|}{$1 \mathrm{mM}$} & \multicolumn{2}{|c|}{$0.1 \mathrm{mM}$} & \multicolumn{2}{|c|}{$0.5 \mathrm{mM}$} & \multicolumn{2}{|c|}{$1 \mathrm{mM}$} \\
\hline & $\begin{array}{l}\text { AVG } \\
\pm \text { SD }\end{array}$ & $\%$ RSD & $\begin{array}{l}\text { AVG } \\
\pm \text { SD }\end{array}$ & $\%$ RSD & $\begin{array}{l}\text { AVG } \\
\pm \text { SD }\end{array}$ & $\%$ RSD & $\begin{array}{l}\text { AVG } \\
\pm \text { SD }\end{array}$ & $\%$ RSD & $\begin{array}{l}\text { AVG } \\
\pm \text { SD }\end{array}$ & $\%$ RSD & $\begin{array}{l}\text { AVG } \\
\pm \text { SD }\end{array}$ & $\%$ RSD \\
\hline $\mathrm{I}_{\mathrm{pc}}$ & $\begin{array}{l}-1.62 \\
\pm 0.02\end{array}$ & -1.50 & $\begin{array}{l}-8.54 \\
\pm 0.24\end{array}$ & -2.77 & $\begin{array}{l}-16.33 \\
\pm 0.46\end{array}$ & -2.82 & $\begin{array}{l}-1.48 \\
\pm 0.02\end{array}$ & -0.97 & $\begin{array}{l}-7.76 \\
\pm 0.04\end{array}$ & -0.46 & $\begin{array}{l}-14.82 \\
\pm 0.57\end{array}$ & -3.85 \\
\hline $\mathrm{I}_{\mathrm{pa}}$ & $\begin{array}{c}1.65 \pm \\
0.03\end{array}$ & 2.00 & $\begin{array}{c}8.40 \pm \\
0.16\end{array}$ & 1.85 & $\begin{array}{c}16.18 \\
\pm 0.46\end{array}$ & 2.86 & $\begin{array}{c}1.47 \pm \\
0.03\end{array}$ & 2.19 & $\begin{array}{c}7.62 \pm \\
0.06\end{array}$ & 0.85 & $\begin{array}{c}14.93 \\
\pm 0.11\end{array}$ & 0.73 \\
\hline
\end{tabular}

$\mathrm{I}_{\mathrm{pc}}$ : cathodic peak current, $\mathrm{I}_{\mathrm{pa}}$ : anodic peak current.

To evaluate the performance of the potentiostats in cyclic voltammetry at various scan rates, cyclic voltammograms were recorded for $1 \mathrm{mM}$ potassium ferricyanide containing $0.1 \mathrm{M} \mathrm{KCl}$ by sweeping the potential from -300 to $600 \mathrm{mV}$ at various scan rates of 5-200 mV/s. Cyclic voltammograms produced on the NFC potentiostat are shown in Figure $4 \mathrm{a}$. When the potential is applied at higher scan rates, higher peak currents are observed because of the decrease in the diffusion layer [47]. Figure $4 \mathrm{~b}$ shows the theoretical linear relationship between the redox peak current of ferricyanide and the square root of the scan rate according to the Randles-Sevcik equation (Equation (1)), indicating that the reaction was a diffusion-controlled process $[47,48]$. Furthermore, the calibration plots obtained from the NFC potentiostat and the commercial potentiostat showed parallel results. A plot from the NFC potentiostat provided a linear slope for cathodic peak current of 1.242 $\mathrm{A} /(\mathrm{V} / \mathrm{s})^{1 / 2}\left(\mathrm{R}^{2}=0.995\right)$ and an anodic peak current of $-1.222 \mathrm{~A} /(\mathrm{V} / \mathrm{s})^{1 / 2}\left(\mathrm{R}^{2}=0.996\right)$. In comparison, the linear slopes for cathodic and anodic peak currents recorded from the commercial potentiostat were $1.237 \mathrm{~A} /(\mathrm{V} / \mathrm{s})^{1 / 2}\left(\mathrm{R}^{2}=0.999\right)$ and $-1.242 \mathrm{~A} /(\mathrm{V} / \mathrm{s})^{1 / 2}$ $\left(R^{2}=0.999\right)$, respectively.

$$
i p=\left[0.4463 n F A C^{0}\left(\frac{n F D}{R T}\right)^{1 / 2}\right] v^{1 / 2}
$$


where ip is the peak current $(\mathrm{A}), \mathrm{n}$ is the number of electrons involved in the redox reaction, $F$ is the Faraday's constant $(96,485 \mathrm{C} / \mathrm{mol}), A$ is the surface area of the working electrode $\left(\mathrm{cm}^{2}\right), C^{0}$ is the concentration of the redox species $\left(\mathrm{mol} / \mathrm{cm}^{3}\right), D$ is the diffusion coefficient of the redox species $\left(\mathrm{cm}^{2} / \mathrm{s}\right), R$ is the universal gas constant $(8.314 \mathrm{~J} / \mathrm{mol} \mathrm{K}), T$ is the absolute temperature $(\mathrm{K})$ and $v$ is the scan rate $(\mathrm{V} / \mathrm{s})$.

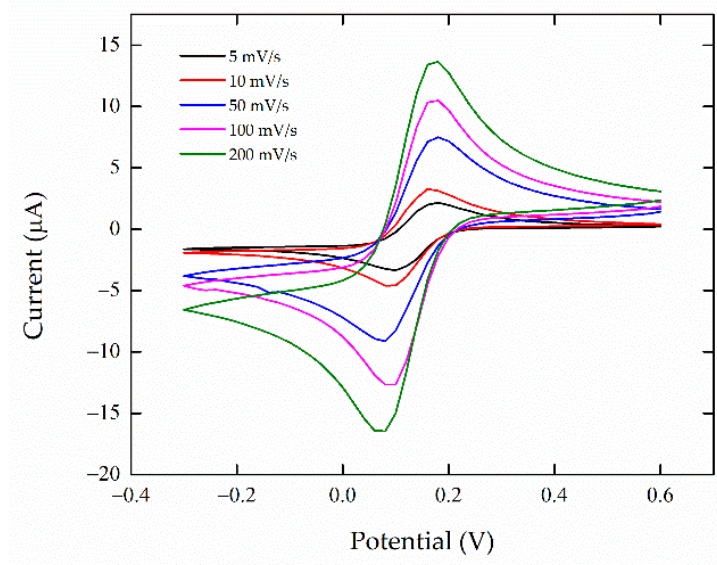

(a)

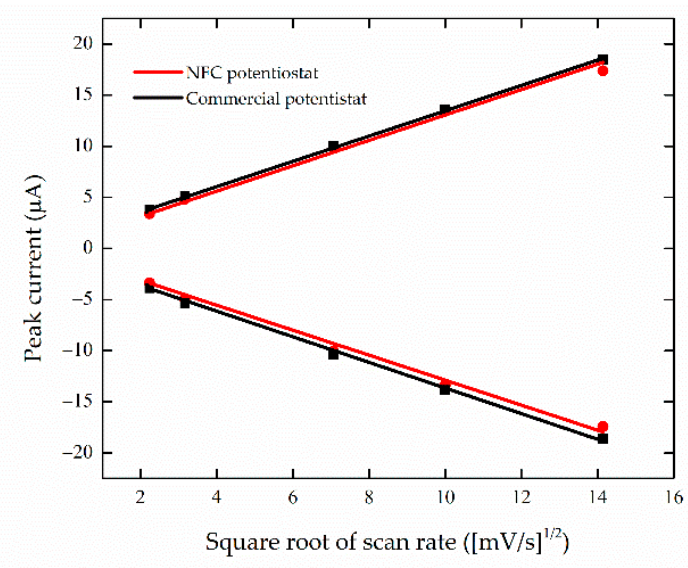

(b)

Figure 4. (a) Cyclic voltammograms of $1 \mathrm{mM}$ potassium ferricyanide/ $0.1 \mathrm{M} \mathrm{KCl}$ on the NFC potentiostat sweeping the potential between -300 and $600 \mathrm{mV}$, at various scan rates. (b) The linear relationship of peak current and square root of scan rate obtained from the NFC potentiostat (red) and the commercial potentiostat (black).

\subsubsection{Chronoamperometry}

To evaluate the performance of the potentiostat in chronoamperometric detection, an experiment was performed with ferricyanide at concentrations ranging from $25-100 \mu \mathrm{M}$. For chronoamperometric detection, a fixed potential was applied at $-100 \mathrm{mV}$ and the measurement period was $30 \mathrm{~s}$. Although the signal response from the NFC potentiostat showed current noise, as shown in Figure 5a, while the current signals from the commercial potentiostat were smooth and free of noise (Figure $5 b$ ), there was good agreement between data obtained by the NFC potentiostat and the commercial potentiostat at different concentrations of ferricyanide (Figure 6a). The final steady-state current after $25 \mathrm{~s}$, calculated as the mean current due to the steady-state value, was proportional to the concentration of the analyte $[49,50]$. Figure $6 \mathrm{~b}$ demonstrates the theoretically expected linear relationship between the current and concentration of ferricyanide. The calibration curve obtained from the commercial potentiostat corresponds to Equation (2) with the regression coefficient as $\mathrm{R}^{2}=0.999$,

$$
\mathrm{y}(\mathrm{I}(\mu \mathrm{A}))=0.0207 \times \mathrm{x}(\mu \mathrm{M}(\mathrm{mol} / \mathrm{L}))+0.0303,
$$

while the calibration curve for the NFC potentiostat was obtained as the following Equation (3) with $\mathrm{R}^{2}=0.998$,

$$
\mathrm{y}(\mathrm{I}(\mu \mathrm{A}))=0.0212 \times \mathrm{x}(\mu \mathrm{M}(\mathrm{mol} / \mathrm{L}))+0.0169 .
$$

The reliability of the potentiostat in detection of the analyte by chronoamperometry was calculated by comparing the slopes between our device and the standard device [51]. The result demonstrated that the reliability was greater than $97 \%$. The average (AVG) and relative standard deviation (RSD) values of the current obtained from both potentiostats are shown in Table 2. The current values obtained from the commercial potentiostat were reproducible with RSD of $\pm 2.55 \%$ and $\pm 3.40 \%$ corresponding to chronoamperometric measurement for $25 \times 10^{-6} \mathrm{M}$ and $1000 \times 10^{-6} \mathrm{M}$, respectively, while the RSD obtained from the NFC potentiostat gave values $\pm 0.91 \%$ and $\pm 7.74 \%$ for $25 \times 10^{-6} \mathrm{M}$ and $1000 \times 10^{-6} \mathrm{M}$, respectively. 


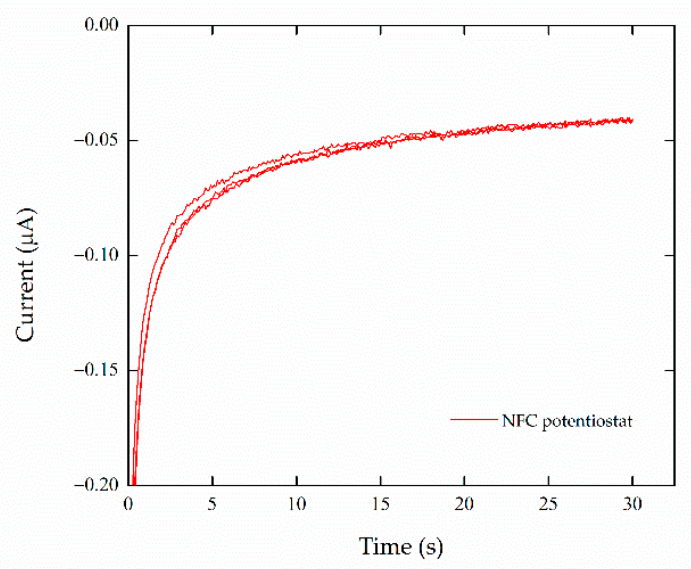

(a)

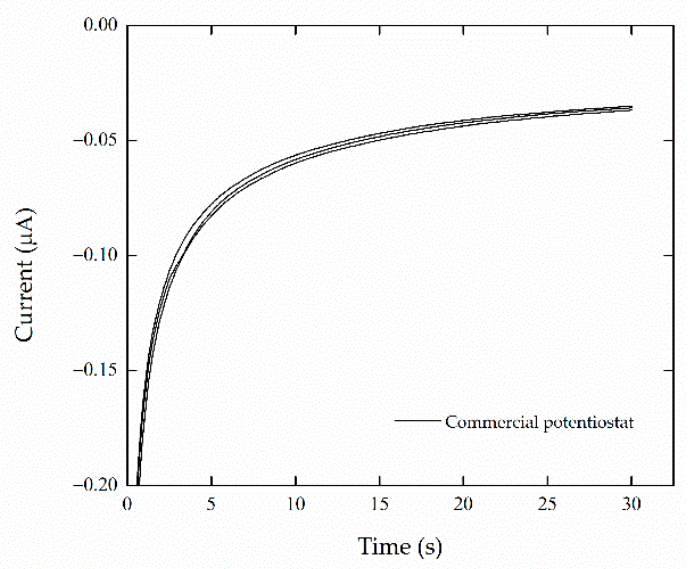

(b)

Figure 5. The chronoamperometric measurement of $25 \mu \mathrm{M}$ ferricyanide measured with (a) NFC potentiostat (red) and (b) commercial potentiostat (black).

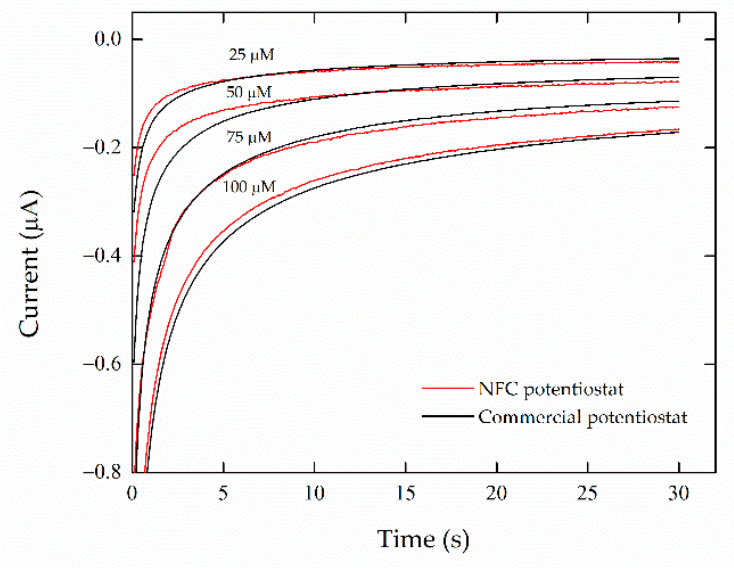

(a)

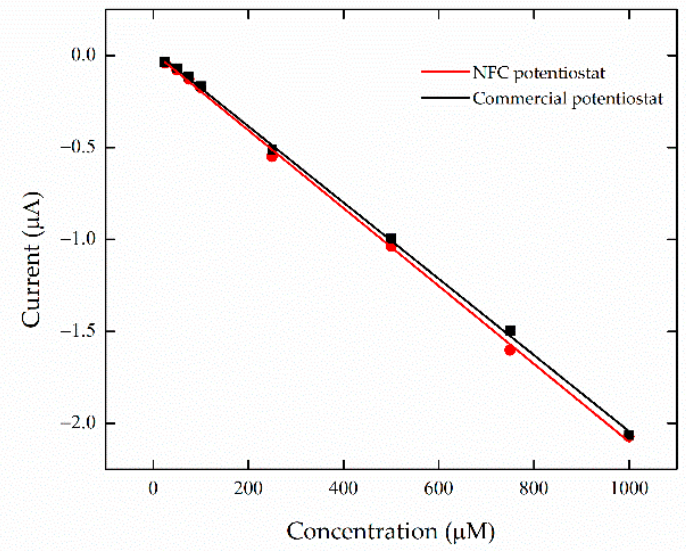

(b)

Figure 6. (a) The chronoamperometry recorded in 25-100 $\mu \mathrm{M}$ ferricyanide solution measured by the NFC potentiostat (red) and the commercial potentiostat (black). (b) The linear correlation between current and concentration of ferricyanide.

Table 2. The average (AVG), standard deviation (SD) and relative standard deviation (RSD) value of the current obtained from both potentiostats in chronoamperometric measurements.

\begin{tabular}{ccccc}
\hline Molarity & \multicolumn{2}{c}{ Commercial Potentiostat } & \multicolumn{2}{c}{ NFC Potentiostat } \\
\hline & AVG $(\mu \mathbf{A}) \pm$ SD & \%RSD & AVG $(\mu \mathbf{A}) \pm$ SD & \%RSD \\
$25 \times 10^{-6}$ & $-0.037 \pm 0.0007$ & -2.55 & $-0.042 \pm 0.0003$ & -0.91 \\
$1000 \times 10^{-6}$ & $-2.064 \pm 0.0572$ & -3.40 & $-2.071 \pm 0.1309$ & -7.74 \\
\hline
\end{tabular}

\subsection{Application of NFC Potentiostat}

To evaluate the application of the NFC potentiostat, it was used to measure the ascorbic acid concentration and determine ascorbic acid in spiked commercial drinking water. The detection limit of standard ascorbic acid was determined by cyclic voltammetry over the potential range from 200 to $800 \mathrm{mV}$. Cyclic voltammograms of different concentrations of ascorbic acid $(0.1-1 \mathrm{mg} / \mathrm{mL})$ are shown in Figure $7 \mathrm{a}$. The current at $550 \mathrm{mV}$ corresponds to the oxidation of ascorbic acid $[19,52]$. Therefore, the current at $550 \mathrm{mV}$ was used to plot the calibration curve as shown in Figure $7 \mathrm{~b}$. The linear regression equation of ascorbic acid measurement was $\mathrm{y}(\mu \mathrm{A})=4.709 \mathrm{x}(\mathrm{mg} / \mathrm{mL})+1.198$, with a correlation coefficient of 
0.998. The limit of detection (LOD) was calculated from $3 \mathrm{~s} / \mathrm{m}$ and the limit of quantitation (LOQ) was obtained from $10 \mathrm{~s} / \mathrm{m}$ where $\mathrm{s}$ is the standard deviation of blank $(n=10)$ and $\mathrm{s}$ is the slope of the calibration curve. According to the equation, the limit of detection and the limit of quantitation were calculated to be $0.0024 \mathrm{mg} / \mathrm{mL}$ and $0.0080 \mathrm{mg} / \mathrm{mL}$, respectively. King et al. reported that the detection limit for measuring ascorbic acid using the pencil electrode was $0.0326 \mathrm{mg} / \mathrm{mL}$ [52]. So, the limit of detection for ascorbic acid determination using a screen-printed carbon electrode in this study was lower than the previous work. The proposed NFC potentiostat was employed to determine ascorbic acid in spiked commercial drinking water. The results are shown in Table 3 . The recoveries were $98.78 \% \pm 4.74,95.80 \% \pm 2.87$ and $92.69 \% \pm 2.35$ for spiking ascorbic acid at concentrations of $0.2,0.4$ and $0.6 \mathrm{mg} / \mathrm{mL}$, respectively. The results indicated that the NFC potentiostat has acceptable accuracy for ascorbic acid measurement.

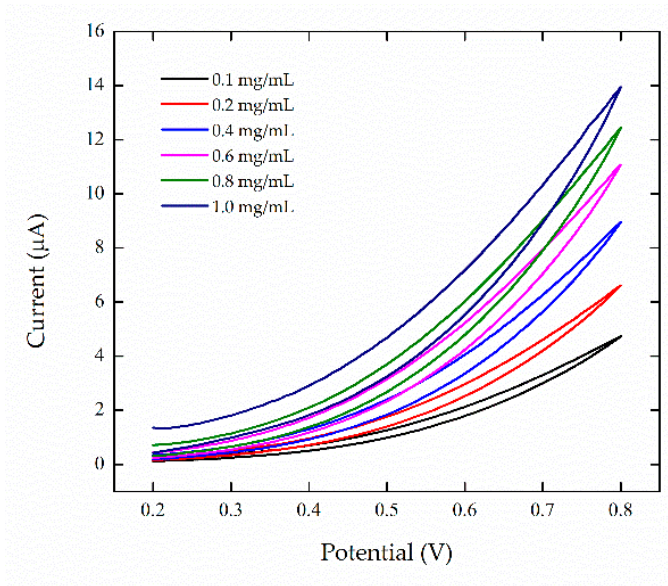

(a)

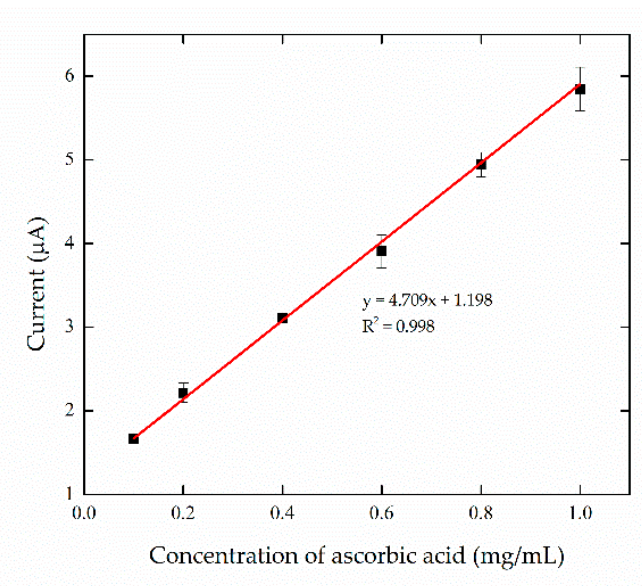

(b)

Figure 7. (a) Cyclic voltammograms of different concentrations of ascorbic acid $(0.1-1.0 \mathrm{mg} / \mathrm{mL}$ ). (b) The calibration curve between current $(\mu \mathrm{A})$ and concentration of ascorbic acid $(\mathrm{mg} / \mathrm{mL})$. The current observed at $550 \mathrm{mV}$ was used to plot the calibration curve to determine the ascorbic acid concentration.

Table 3. Analyses of ascorbic acid in spiked commercial drinking water measured by cyclic voltammetry $(n=3)$.

\begin{tabular}{ccc}
\hline Sample Added $(\mathrm{mg} / \mathrm{mL})$ & Found $(\mathrm{mg} / \mathrm{mL})$ & Recovery $\mathbf{( \% )}$ \\
\hline 0.2 & $0.197 \pm 0.009$ & $98.78 \pm 4.74$ \\
0.4 & $0.383 \pm 0.011$ & $95.80 \pm 2.87$ \\
0.6 & $0.556 \pm 0.014$ & $92.69 \pm 2.35$ \\
\hline
\end{tabular}

\section{Discussion}

This study demonstrated the design and performance of an NFC potentiostat (Silicon Craft Technology PLC, Bangkok, Thailand), which is a battery-free and flat card-sized device that interfaces with a smartphone through near-field communication. The device was designed for electrochemical measurement in point-of-care testing and resource-limited settings that do not require technical users. These potentiostats have the following aspects: (1) portability: the device is credit-card-sized $(5.5 \mathrm{~cm} \times 8.6 \mathrm{~cm})$ and weighs only $8.07 \mathrm{~g}$; (2) low cost: this potentiostat is designed to be used with a screen-printed electrode, which is low-cost, disposable and has ease of modification to detect various analytes [53,54]; (3) ease of use: the NFC potentiostat is operated via a smartphone application. The smartphone application allows the user to set the parameters of an electrochemical experiment and receive the resulting data; (4) wireless and cloud connectivity: the connection of smartphones facilitates sharing and storage of all information to the database in order to minimize the 
manual error and create big data for further analysis, such as machine learning or artificial intelligence.

The performance of the NFC potentiostat was evaluated by comparing it to a commercial benchtop potentiostat. Cyclic voltammetry and chronoamperometry were carried out in a potassium ferricyanide solution containing $0.1 \mathrm{M} \mathrm{KCl}$. The results showed good agreement of cyclic voltammograms between the two devices, but current signals of our NFC potentiostat were lower than the commercial potentiostat. The deviation was from the difference of applied potential step voltage from the DAC and differences in sampling time and period designed for each potentiostat. For amperometric measurements, the slope of the current response obtained by the NFC potentiostat was similar to the commercial potentiostat with a reliability greater than $97 \%$, although the signal from the NFC potentiostat was observed to have current noise, compared with the commercial potentiostat, which was free of noise. The noise was from a limitation of the analog-to-digital converter (ADC) resolution of the potentiostat, which is 12 bit and less than that of the commercial benchtop potentiostat. Note that the setting measurement range was $\pm 20 \mu \mathrm{A}$, hence, the noise floor should be around $10 \mathrm{nA}$.

The first prototype of the NFC potentiostat can perform cyclic voltammetry and chronoamperometry with the input current $\pm 20 \mu \mathrm{A}$ and the biasing voltage at $\pm 0.8 \mathrm{~V}$. Although the benchtop potentiostats offer a wide operational window of current and voltage $( \pm 2 \mathrm{~A}, \pm 10 \mathrm{~V})$, they are too expensive and large for on-site measurement. Therefore, an NFC potentiostat can be an alternative device for electrochemical measurement in pointof-care testing and resource-limited settings. In a future prototype, the operation ranges will be expanded and the system will be developed to support various electrochemical techniques such as linear sweep voltammetry, square wave voltammetry and differential pulse voltammetry.

\section{Conclusions}

This study demonstrated the design and performance of an NFC potentiostat developed by Silicon Craft Technology PLC (Bangkok, Thailand). The NFC potentiostat is a flat, card-sized, lightweight device and is operated using an NFC smartphone, so it is portable and easy to use. The performance of the NFC potentiostat exhibits a good agreement with a commercial benchtop potentiostat for both cyclic voltammetry and chronoamperometry. The application of this device was demonstrated through its use in ascorbic acid measurement. This platform is suitable for various analytes, depending on the design and modification of the electrodes used as a sensor. Therefore, an NFC potentiostat can be an alternative device for electrochemical measurement in point-of-care testing and resource-limited settings in many fields, including healthcare, agriculture and the environment.

Supplementary Materials: The following are available online at https:/ / www.mdpi.com/2076-341 7/11/1/392/s1, Video S1: Demonstration of NFC potentiostat operation. A $100 \mu \mathrm{L}$ of $1.0 \mathrm{mg} / \mathrm{mL}$ ascorbic acid was drop-cast on screen-printed carbon electrode, followed by a cyclic voltammetry measurement by NFC potentiostat.

Author Contributions: Conceptualization, K.K., S.K. (Sirinan Kulchat) and R.P.; Formal analysis, K.K., and S.K. (Supannika Klangphukhiew); Funding acquisition, R.P.; Methodology, K.K., and S.K. (Supannika Klangphukhiew); Project administration, R.P.; Writing—original draft, K.K.; Writingreview and editing, S.K. (Supannika Klangphukhiew), S.K. (Sirinan Kulchat) and R.P. All authors have read and agreed to the published version of the manuscript.

Funding: This research was fund by the National Innovation Agency, Silicon Craft Technology PLC, the Center of Excellence on Medical Biotechnology [CD-61-005], Science and Technology Postgraduate Education and Research Development Office, the Office of Higher Education Commission of Thailand and the Science Achievement Scholarship of Thailand.

Institutional Review Board Statement: Not applicable.

Informed Consent Statement: Not applicable. 
Data Availability Statement: The data presented in this study are available within the article and its supplementary materials.

Acknowledgments: The authors would like to thank Silicon Craft Technology PLC (www.sic.co.th) for developing the NFC potentiostat and providing the prototype to use in this study. We also thank Jyh-Myng Zen's Laboratory from the Department of Chemistry, Faculty of Science, Chung-Hsing University, Taiwan, for providing the electrochemical device (CHI 611E, Texas Instruments Inc., Austin, TX, USA)and laboratory facilities to conduct the experiments.

Conflicts of Interest: The authors declare no conflict of interest.

\section{References}

1. Kurbanoglu, S.; Erkmen, C.; Uslu, B. Frontiers in Electrochemical Enzyme Based Biosensors for Food and Drug Analysis. Trends Anal. Chem. 2020, 124, 115809. [CrossRef]

2. Campuzano, S.; Yanez-Sedeno, P.; Pingarron, J.M. Electrochemical Affinity Biosensors Based on Selected Nanostructures for Food and Environmental Monitoring. Sensors 2020, 20, 5125. [CrossRef] [PubMed]

3. Torre, R.; Costa-Rama, E.; Nouws, H.P.A.; Delerue-Matos, C. Screen-Printed Electrode-Based Sensors for Food Spoilage Control: Bacteria and Biogenic Amines Detection. Biosensors 2020, 10, 139. [CrossRef] [PubMed]

4. Khanmohammadi, A.; Jalili Ghazizadeh, A.; Hashemi, P.; Afkhami, A.; Arduini, F.; Bagheri, H. An Overview to Electrochemical Biosensors and Sensors for the Detection of Environmental Contaminants. J. Iran. Chem. Soc. 2020, 17, 2429-2447. [CrossRef]

5. Yan, K.; Karthick Kannan, P.; Doonyapisut, D.; Wu, K.; Chung, C.H.; Zhang, J. Advanced Functional Electroactive and Photoactive Materials for Monitoring the Environmental Pollutants. Adv. Funct. Mater. 2020, 2008227. [CrossRef]

6. Williams, D.E. Electrochemical Sensors for Environmental Gas Analysis. Curr. Opin. Electrochem. 2020, 22, 145-153. [CrossRef]

7. Maduraiveeran, G. Bionanomaterial-Based Electrochemical Biosensing Platforms for Biomedical Applications. Anal. Methods 2020, 12, 1688-1701. [CrossRef]

8. Mohankumar, P.; Ajayan, J.; Mohanraj, T.; Yasodharan, R. Recent Developments in Biosensors for Healthcare and Biomedical Applications: A Review. Measurement 2021, 167, 108293. [CrossRef]

9. Mincu, N.B.; Lazar, V.; Stan, D.; Mihailescu, C.M.; Iosub, R.; Mateescu, A.L. Screen-Printed Electrodes (SPE) for In Vitro Diagnostic Purpose. Diagnostics 2020, 10, 517. [CrossRef]

10. Huang, Y.; Xu, J.; Liu, J.; Wang, X.; Chen, B. Disease-Related Detection with Electrochemical Biosensors: A Review. Sensors 2017, 17, 2375. [CrossRef]

11. Huang, L.; Tian, S.; Zhao, W.; Liu, K.; Guo, J. Electrochemical Vitamin Sensors: A Critical Review. Talanta 2021, $222,121645$. [CrossRef] [PubMed]

12. Banerjee, S.; McCracken, S.; Hossain, M.F.; Slaughter, G. Electrochemical Detection of Neurotransmitters. Biosensors 2020, 10 , 101. [CrossRef] [PubMed]

13. Sun, A.C.; Hall, D.A. Point-of-Care Smartphone-Based Electrochemical Biosensing. Electroanalysis 2019, 31, 2-16. [CrossRef]

14. Bezuidenhout, P.; Smith, S.; Joubert, T.-H. A Low-Cost Inkjet-Printed Paper-Based Potentiostat. Appl. Sci. 2018, 8, 968. [CrossRef]

15. Metrohm Autolab PGSTAT 302N. Available online: http://eqdb.nrf.ac.za/equipment/other/metrohm-autolab-pgstat-302n (accessed on 16 December 2020).

16. EmStat3. Available online: https://www.palmsens.com/product/emstat/ (accessed on 16 December 2020).

17. Potentiostats. Available online: https://www.biologic.net/product_category/potentiostats-galvanostats/ (accessed on 16 December 2020).

18. Dobbelaere, T.; Vereecken, P.M.; Detavernier, C. A USB-Controlled Potentiostat/Galvanostat for Thin-Film Battery Characterization. HardwareX 2017, 2, 34-49. [CrossRef]

19. Rowe, A.A.; Bonham, A.J.; White, R.J.; Zimmer, M.P.; Yadgar, R.J.; Hobza, T.M.; Honea, J.W.; Ben-Yaacov, I.; Plaxco, K.W. Cheapstat: An Open-Source, "Do-It-Yourself" Potentiostat for Analytical and Educational Applications. PLoS ONE 2011, 6, e23783. [CrossRef]

20. Lopin, P.; Lopin, K.V. PSoC-Stat: A Single Chip Open Source Potentiostat Based on a Programmable System on a Chip. PLoS ONE 2018, 13, e0201353. [CrossRef]

21. Dryden, M.D.; Wheeler, A.R. DStat: A Versatile, Open-Source Potentiostat for Electroanalysis and Integration. PLoS ONE 2015, 10, e0140349. [CrossRef]

22. Smartphone Users Worldwide 2016-2021. Available online: https://www.statista.com/statistics/330695/number-of-smartphoneusers-worldwide/ (accessed on 9 November 2020).

23. Xu, G.; Cheng, C.; Yuan, W.; Liu, Z.; Zhu, L.; Li, X.; Lu, Y.; Chen, Z.; Liu, J.; Cui, Z.; et al. Smartphone-Based Battery-Free and Flexible Electrochemical Patch for Calcium and Chloride Ions Detections in Biofluids. Sens. Actuators B Chem. 2019, $297,126743$. [CrossRef]

24. Ainla, A.; Mousavi, M.P.S.; Tsaloglou, M.N.; Redston, J.; Bell, J.G.; Fernandez-Abedul, M.T.; Whitesides, G.M. Open-Source Potentiostat for Wireless Electrochemical Detection with Smartphones. Anal. Chem. 2018, 90, 6240-6246. [CrossRef]

25. Cai, X.; Gao, Q.; Zuo, S.; Zhao, H.; Lan, M. Smartphone-coupled Electrochemical Analysis of Cellular Superoxide Anions Based on $\mathrm{Mn}_{\mathrm{x}}\left(\mathrm{PO}_{4}\right)_{\mathrm{y}}$ Monolayer Modified Porous Carbon. Electroanalysis 2019, 32, 598-605. [CrossRef] 
26. Jenkins, D.M.; Lee, B.E.; Jun, S.; Reyes-De-Corcuera, J.; McLamore, E.S. ABE-Stat, a Fully Open-Source and Versatile Wireless Potentiostat Project Including Electrochemical Impedance Spectroscopy. J. Electrochem. Soc. 2019, 166, B3056-B3065. [CrossRef]

27. Xu, G.; Cheng, C.; Liu, Z.; Yuan, W.; Wu, X.; Lu, Y.; Low, S.S.; Liu, J.; Zhu, L.; Ji, D.; et al. Battery-Free and Wireless Epidermal Electrochemical System with All-Printed Stretchable Electrode Array for Multiplexed In Situ Sweat Analysis. Adv. Mater. Technol. 2019, 4, 1800658. [CrossRef]

28. Escobedo, P.; Erenas, M.M.; Martinez-Olmos, A.; Carvajal, M.A.; Gonzalez-Chocano, S.; Capitan-Vallvey, L.F.; Palma, A.J. General-Purpose Passive Wireless Point-of-Care Platform Based on Smartphone. Biosens. Bioelectron. 2019, 141, 111360. [CrossRef] [PubMed]

29. Novell, M.; Guinovart, T.; Steinberg, I.M.; Steinberg, M.; Rius, F.X.; Andrade, F.J. A novel miniaturized radiofrequency potentiometer tag using ion-selective electrodes for wireless ion sensing. Analyst 2013, 138, 5250-5257. [CrossRef] [PubMed]

30. Lazaro, A.; Villarino, R.; Girbau, D. A Survey of NFC Sensors Based on Energy Harvesting for IoT Applications. Sensors 2018, 18, 3746. [CrossRef] [PubMed]

31. Cao, Z.; Chen, P.; Ma, Z.; Li, S.; Gao, X.; Wu, R.X.; Pan, L.; Shi, Y. Near-Field Communication Sensors. Sensors 2019, 19 , 3947. [CrossRef]

32. Nguyen, T.B.; Nguyen, T.H.; Chung, W.Y. Battery-Free and Noninvasive Estimation of Food pH and $\mathrm{CO}_{2}$ Concentration for Food Monitoring Based on Pressure Measurement. Sensors 2020, 20, 5853. [CrossRef]

33. Nguyen, T.B.; Tran, V.T.; Chung, W.Y. Pressure Measurement-Based Method for Battery-Free Food Monitoring Powered by NFC Energy Harvesting. Sci. Rep. 2019, 9, 17556. [CrossRef]

34. Eldebiky, A.; Elsobky, M.; Richter, H.; Burghartz, J.N. Humidity and Temperature Sensor System Demonstrator with NFC Tag for HySiF Applications. Adv. Radio Sci. 2018, 16, 109-116. [CrossRef]

35. Azzarelli, J.M.; Mirica, K.A.; Ravnsbaek, J.B.; Swager, T.M. Wireless Gas Detection with a Smartphone via Rf Communication. Proc. Natl. Acad. Sci. USA 2014, 111, 18162-18166. [CrossRef] [PubMed]

36. Xu, G.; Zhang, Q.; Lu, Y.; Liu, L.; Ji, D.; Li, S.; Liu, Q. Passive and Wireless Near Field Communication Tag Sensors for Biochemical Sensing with Smartphone. Sens. Actuators B Chem. 2017, 246, 748-755. [CrossRef]

37. Bouklachi, M.; Biancheri-Astier, M.; Diet, A.; Le Bihan, Y. NFC/RFID Patch Coil Curvature Effect and Shielding for Medical Applications Wirelessly Powered. IEEE J. Radio Freq. Identif. 2020, 4, 107-114. [CrossRef]

38. Kollegger, C.; Greiner, P.; Siegl, I.; Steffan, C.; Wiessflecker, M.; Pekec, B.; Hajnsek, M.; Sinner, F.; Holweg, G.; Deutschmann, B. Intelligent NFC Potassium Measurement Strip with Hemolysis Check in Capillary Blood. Elektrotechnik Inf. 2018, 135, 83-88. [CrossRef]

39. Strömmer, E.; Hillukkala, M.; Ylisaukko-oja, A. Ultra-low Power Sensors with Near Field Communication for Mobile Applications. In Proceedings of Wireless Sensor and Actor Networks; Springer: Boston, MA, USA, 2007; pp. 131-142.

40. Kassal, P.; Steinberg, I.M.; Steinberg, M.D. Wireless Smart Tag with Potentiometric Input for Ultra Low-Power Chemical Sensing. Sens. Actuators B Chem. 2013, 184, 254-259. [CrossRef]

41. Steinberg, M.D.; Kassal, P.; Kerekovic, I.; Steinberg, I.M. A Wireless Potentiostat for Mobile Chemical Sensing and Biosensing. Talanta 2015, 143, 178-183. [CrossRef]

42. Kassal, P.; Kim, J.; Kumar, R.; De Araujo, W.R.; Steinberg, I.M.; Steinberg, M.D.; Wang, J. Smart Bandage with Wireless Connectivity for Uric Acid Biosensing as an Indicator of Wound Status. Electrochem. Commun. 2015, 56, 6-10. [CrossRef]

43. Fedtschenko, T.; Utz, A.; Stanitzki, A.; Hennig, A.; Ludecke, A.; Haas, N.; Kokozinski, R. A New Configurable Wireless Sensor System for Biomedical Applications with ISO 18000-3 Interface in $0.35 \mu \mathrm{m}$ CMOS. Sensors 2019, 19, 4110. [CrossRef]

44. Siegl, I.; Kollegger, C.; Rabl, C.; Steffan, C.; Pribyl, W. NFC Powered Cyclic Voltammetry with Dynamic Output Voltage Range Exploitation. In Proceedings of the 2018 12th International Conference on Sensing Technology (ICST), Limerick, Ireland, 4-6 December 2018; pp. 407-412.

45. Munoz-Martinez, A.I.; Pena, O.I.G.; Colomer-Farrarons, J.; Rodriguez-Delgado, J.M.; Avila-Ortega, A.; Dieck-Assad, G. Electrochemical Instrumentation of an Embedded Potentiostat System (EPS) for a Programmable-System-On-a-Chip. Sensors 2018, 18, 4490. [CrossRef]

46. Gopinath, A.V.; Russell, D. An Inexpensive Field-Portable Programmable Potentiostat. Chem. Educ. 2006, 11, 22-28. [CrossRef]

47. Elgrishi, N.; Rountree, K.J.; McCarthy, B.D.; Rountree, E.S.; Eisenhart, T.T.; Dempsey, J.L. A Practical Beginner's Guide to Cyclic Voltammetry. J. Chem. Educ. 2018, 95, 197-206. [CrossRef]

48. Li, Y.C.; Melenbrink, E.L.; Cordonier, G.J.; Boggs, C.; Khan, A.; Isaac, M.K.; Nkhonjera, L.K.; Bahati, D.; Billinge, S.J.; Haile, S.M.; et al. An Easily Fabricated Low-Cost Potentiostat Coupled with User-Friendly Software for Introducing Students to Electrochemical Reactions and Electroanalytical Techniques. J. Chem. Educ. 2018, 95, 1658-1661. [CrossRef]

49. Guo, J.; Ma, X. Simultaneous Monitoring of Glucose and Uric Acid on a Single Test Strip with Dual Channels. Biosens. Bioelectron. 2017, 94, 415-419. [CrossRef] [PubMed]

50. Nemiroski, A.; Christodouleas, D.C.; Hennek, J.W.; Kumar, A.A.; Maxwell, E.J.; Fernandez-Abedul, M.T.; Whitesides, G.M. Universal Mobile Electrochemical Detector Designed for Use in Resource-Limited Applications. Proc. Natl. Acad. Sci. USA 2014, 111, 11984-11989. [CrossRef]

51. Aznar-Poveda, J.; Lopez-Pastor, J.A.; Garcia-Sanchez, A.J.; Garcia-Haro, J.; Otero, T.F. A COTS-Based Portable System to Conduct Accurate Substance Concentration Measurements. Sensors 2018, 18, 539. [CrossRef] 
52. King, D.; Friend, J.; Kariuki, J. Measuring Vitamin C Content of Commercial Orange Juice Using a Pencil Lead Electrode. J. Chem. Educ. 2010, 87, 507-509. [CrossRef]

53. Renedo, O.D.; Alonso-Lomillo, M.A.; Martinez, M.J. Recent Developments in the Field of Screen-Printed Electrodes and Their Related Applications. Talanta 2007, 73, 202-219. [CrossRef]

54. Beitollahi, H.; Mohammadi, S.Z.; Safaei, M.; Tajik, S. Applications of Electrochemical Sensors and Biosensors Based on Modified Screen-Printed Electrodes: A Review. Anal. Methods 2020, 12, 1547-1560. [CrossRef] 